\title{
Systematic Reviews and Meta-Analysis Applied to Ethnobiological Research
}

\author{
Ulysses Paulino Albuquerque ${ }^{1, *}$ and Patrícia Muniz de Medeiros ${ }^{1,2}$
}

\footnotetext{
${ }^{1}$ Laboratório de Etnobotânica Aplicada. Departamento de Biologia. Universidade Federal Rural de Pernambuco. Rua Dom Manoel de Medeiros s/n, 52171-900, Dois Irmãos, Recife-PE, Brazil.

${ }^{2}$ Instituto de Ciências Biológicas e Desenvolvimento Sustentável. Universidade Federal da Bahia.

Estrada do Barrocão, s/n, 47800-000, Morada Nobre, Barreiras-BA, Brazil.

* Corresponding author

\E-mail adresses: UPA (upa@db.ufrpe.br), PMM (patricia.muniz@gmail.com)
}

Ethnobiology and Conservation 2012, 1: 6 (8 October 2012) ISSN 2238-4782

\section{Abstract}

We suggest the application of systematic reviews and meta-analysis to access biological resource selection and use patterns from a regional or global point of view. In this opinion paper, we discuss the importance of this approach to help advancing the comprehension of socio-ecological systems at broad temporal and spatial scales.

Keywords: Ethnobiology - Traditional Biological Knowledge - Quantitative analysis 


\section{Introduction}

Ethnobiology has grown considerably in the last 10 years, especially in developing countries, as evidenced by a number of publications in long-standing ethnobiological journals (Journal of Ethnobiology, also Economic Botany, Journal of Ethnophamacology) and the addition of several new journals (including Ethnobiology Letters, Journal of Ethnobiology and Ethnomedicine, Ethnobotany Research \& Applications and Ethnobiology and Conservation). Despite this growth, we have noticed that discussions focusing on theoretical and methodological aspects of the area are scarce (see discussion in Albuquerque and Hanazaki 2009; Albuquerque and Hurrell 2010; Alves and Albuquerque 2010). In a large number of ethnobiological scientific publications, the authors do not explicitly state the hypotheses or questions that guided the inquiry. Additionally, most of the hypothesis and theories cited in ethnobiological studies come from other disciplines, such as classic anthropology and ecology (see, for example, Soldati and Albuquerque 2012). Undoubtedly, this situation reflects the still incipient development of ethnobiology.

Several studies have repeated the same phrase, "each culture has its own unique relationship with natural resources," without further evaluation. Though true, statements like this could lead to the misunderstanding that we cannot identify patterns in the relationship between people and plants, given that each experience is unique. Certainly, each culture has a particular relationship with its resources; however, that is not to say that such experiences do not reflect patterns and behaviors that are highly similar in different cultures and regions. In addition, the lack of a unifying theory and/or common inquiry goals makes it difficult to clearly recognize patterns if they do occur. Several studies in ethnobotany, for example, have tried to address broad comparisons (see Bletter 2007; Moerman et al. 1999), but in many cases such comparisons are difficult or even impossible given the diversity of the methods employed. Thus, it is not easy to make generalizations, even considering all available information on a certain topic.

We believe that ethnobiologists must discuss their common points of interest, identify the major themes of investigation, and generate strategies to make it possible to compare the research data collected from different regions. Meanwhile, we propose an investigation program based on the use of systematic reviews and metaanalysis to search for regional or global patterns. The approach defined here is directly influenced by an emergent subfield of ecology, namely, macroecology and, thus, might be termed "macroethnobiology". Macroecology deals with the study of relationships between organisms and their environment, which involves characterizing and explaining statistical patterns of abundance, distribution, and diversity (Brown 2003). A macroecological approach, therefore, emphasizes description and explanation of processes that occur on global or regional spatial scales and on temporal scales that vary from decades to millennia (Brown 2003; Smith et al. 2008). Macroecology was originally framed in 1989 with a study of datasets encompassing several types of organisms that evaluated the assembly of continental biota to uncover how physical space and the nutritional resources are divided among resident species across large geographic areas (Brown and Maurer 1989).

Following this pioneering study, several investigations evaluated aspects of species distribution from a macroecological perspective (Jennins and Blanchard 2004; Kelt and Van Vurren 2001; Li 2002; Taylor and Gotelli 1994; Vaughn and Taylor 2000). Additionally, papers framing and evaluating macroecological methods, 
tools, and principles have become available (Blackburn 2004; Gaston and Blackburn 1999; Isaac et al. 2004; Rangel et al. 2006), as well as textbooks on the theme (Brown 2003; Gaston and Blackburn 2000). Generally, macroecological studies analyze results from primary studies to discern global and regional profiles. This perspective, distinct from that of traditional ecology, was widely criticized, primarily for being a program of non-experimental investigation. These criticisms actually contributed to the growth of the area; that is, macroecologists worked at detailing the logic of the approach and showed that macroecology follows all the rules of Western science (Blackburn 2004; Brown 2003). Macroacroecology therefore, generates global strategies for issues such as biodiversity conservation (Brown 2003).

\section{What are we suggesting?}

Following the tenets of macroecology, we propose an adaptation of macroscopic analysis to ethnobiology. Macroscopic analysis in ethnobiology does not disregard culture as one of the modulating agents of the relationship between people and biological resources nor consider that all human populations have identical behaviors regarding the knowledge and use of natural resources. Instead, such analysis focuses on phenomena that are the product of these interactions and characteristics that tend to be repeated in different places. Evidence of such patterns can be useful in generating strategies for conservation or bioprospecting, for example, on a regional scale, without disregarding the peculiarities and characteristics inherent to these regions.

With the goal of ascertaining possible regional patterns in the knowledge and use of plant resources, the macroscopic approach aims to extend analysis to areas much larger than those found on the local scale (e.g., a community, village or city). The analysis of secondary data is therefore one of the main tools for this type of approach. However, considering the scenario that we outlined, it is necessary to derive data of excellent quality to avoid biases in interpretation once aggregated datasets are assembled. We want to highlight three main points:

1. The macroscopic approach to ethnobiology is not an academic discipline, but a way to understand the complexity of the relationship between people and biological resources on a global or regional scale.

2. We are not only suggesting the compilation of secondary data or literature review; but rather a statistical analysis of secondary data from different studies.

3. As for any other study based on the hypothetic-deductive method, the questions that guide the investigation must be clear, objective, and designed to contribute to the understanding of a given phenomenon.

In fact, some previous works in ethnobiology can be considered precursors of this approach, as they seek to determine regional or global patterns concerning the relationship between people and living beings. However, they use different approaches which do not fit to our proposal of using systematic reviews and metaanalysis. The Berlinean classification (Berlin 1992), for example, has suggested patterns of plant and animal classification based on a hierarchical perception. Moerman (1979) compiled the North American medicinal flora and compared it to the total flora of the region. This work was an attempt to find overused and underused botanical families and to show that medicinal plant use performed by traditional societies is not randomly performed, but rather based on efficiency, what could explain the statistical underuse and overuse of certain families. This idea was followed by a number of further works (Amiguet et al. 2006; Bourbonnais-Spear et al. 
2005; Douwes et al. 2008; Hernández et al. 2005; Kapur et al. 1992; Leonti et al. 2003; Moerman 1989; Moerman 1991; Moerman 1996; Moerman et al. 1999; SaslisLagoudakis et al. 2011). Some other studies compiled published information and treated them quantitatively in order to find plant use patterns (Albuquerque et al. 2007; Molares e Ladio 2009).

The difference between the approach suggested here and those cited above is mainly methodological. We suggest the use of systematic reviews (Cooper 2009) and meta-analysis to analyze plant use and selection patterns. This perspective has not been applied to ethnobiological works so far. Glass (1976) created the term metaanalysis to differentiate statistical analysis of the results of individual studies from the integration of such results. A relative lack of quantitative approaches and experimental design targeted at the questions and hypotheses may have contributed to the lack of interest in meta-analysis in the field of ethnobiology. Despite the limitations imposed by the nature of ethnobiological research, some of its areas can readily assimilate meta-analytical tools. Studies of the use patterns of medicinal plants and animals have great potential because a majority of such studies provide complete lists of useful animals and plants despite a lack of common questions and an absence of statistical analysis. These lists allow for later calculation of basic statistics and the secondary testing of hypotheses that are broader in temporal and geographic scale.

Possible studies might consider following suggestions:

1. The influence of migration on the selection and use of medicinal resources. Several studies have examined the use of medicinal plants by migrant groups (Balick et al. 2000; Capps 2009; Ceuterick et al. 2008; Medeiros et al. 2012; Nesheim et al. 2006; Pieroni and Gray 2008; Volpato et al. 2009). Systematic reviews can contribute to clarification of information such as the main strategy used by migrants (to obtain plants from their original habitat or to adapt themselves to new plants) or how migration results in the increase or reduction of medicinal plants available in the new habitat.

2. The influence of socioeconomic variables on the knowledge and use of plants or animals. Several studies have used correlation or regression analyses to evaluate whether variables such as income, age, gender, occupation or time of residence affect the knowledge or use of plants, among other resources (Cocks et al. 2008; Fisher 1999; Gavin and Anderson 2007; Monteiro et al. 2006; Tekleyhamanot et al. 2007). Macroscopic analysis can help us to understand the predictive power of these variables at larger scales.

3. Research on public markets has been frequent in ethnobotany (Monteiro et al. 2010). Several studies in this area are essentially descriptive and individual studies do not very reveal general patterns. Markets are an important source of research to ethnobiologists because several hypotheses can be tested there. How much does the biological diversity of markets reflect the biological diversity in the region? What is the predictive power of the demand (or supply and demand) on biological resources sold in the markets?

4. One hypothesis that has been tested often in ethnobotany is: plants that are used more frequently by local populations are available in greater numbers in the environment (Lucena et al. 2007; Phillips and Gentry 1993). The combination of data from different studies can answer how the abundance of a given resource influences its local importance for human populations. 


\section{Final Remarks}

The application of systematic reviews and meta-analysis to ethnobiology does not intend to be a new subfield or to supplant other approaches, but rather should incorporate additional ways to assess large-scale patterns. Considering that we are still advancing in ethnobiological researches, why is meta-analytical approach necessary? The proposed approach is "top-down" and it considers that macrogeographic ethnobiological patterns are not necessarily evident in the isolated case studies. The logic of this meta-analytical approach requires accepting the idea that previously unrecognized properties can emerge from the sum of parts. Conventional ethnobiological studies and those which were proposed here can be developed together in order to better understand the processes and patterns that explain the complex socio-ecological systems.

\section{Acknowledgements}

We thank CNPq for the financial support and research productivity scholarship granted to the first author and for the scholarship awarded to P.M. Medeiros.

\section{References}

Albuquerque UP, Medeiros PM, Almeida AL, Monteiro JM, Lins Neto EMF, Melo JG, Santos JP (2007) Medicinal plants of the caatinga (semi-arid) vegetation of NE Brazil: a quantitative approach. Journal of Ethnopharmacology 114: 325-354.

Albuquerque UP, Hanazaki N (2009) Five problems in current ethnobotanical research - and some suggestions for strengthening them. Human Ecology 37: 653-661.

Albuquerque UP, Hurrell JA (2010) Ethnobotany: one concept and many interpretations. In: Albuquerque UP, Hanazaki N (eds) Recent Developments and Case Studies in Ethnobotany. Sociedade Brasileira de Etnobiologia e Etnoecologia/NUPEEA, Recife, pp. 87-99.

Alves AGC, Albuquerque UP (2010) "Ethno what?" Terminological problems in ethnoscience with a special emphasis on the Brazilian context. In: Albuquerque UP, Hanazaki N (eds) Recent Developmentes and Case Studies in Ethnobotany. Sociedade Brasileira de Etnobiologia e Etnoecologia/NUPEEA, Recife, pp. 67-79.

Amiguet VT, Arnason JT, Maquin P, Cal V, Nchez-vindas PS, Alvarez LP (2006) A regression analysis of Q'eqchi' Maya Medicinal plants from southern Belize. Economic Botany 60(1): 24-38.

Balick MJ, Kronenberg F, Ososki AL, Reiff M, Fugh-Berman A, Connor BO, Roble M, Lohr P, Atha D (2000) Medicinal Plants Used By Latino Healers for Women's Health Conditions in New York City. Economic Botany 54: 344-357.

Berlin B. (1992) Ethnobiological classification. Principles of categorization of plant and animalsin traditional societies. Princeton University Press, Princeton.

Blackburn TM (2004) Method in Macroecology. Basic and Applied Ecology 5: 401412. 
Bletter N (2007) A quantitative synthesis of the medicinal ethnobotany of the Malinké of Mali and the Asháninka of Peru, with a new theoretical framework. Journal of Ethnobiology and Ethnomedicine 3, 36.

Bourbonnais-Spear N, Awad R, Maquin P, Cal V, Sanchez Vindas P, Poveda L, Arnason JT (2005) Plant Use by the Q'eqchi' Maya of Belize in Ethnopsychiatry and Neurological Pathology. Economic Botany 59(4): 326-336.

Brown JH, Maurer BA (1989) Macroecology: The Division of Food and Space among Species on Continents. Science 243: 1145-50.

Brown JH (2003) Macroecologia. Fce, México.

Capps LL (2009) Change and Continuity in the Medical Culture of the Hmong in Kansas City. Medical Anthropology 8: 161-177.

Ceuterick M, Vandebroek I, Torry B, Pieroni A (2008) Cross-Cultural Adaptation in Urban Ethnobotany: The Colombian Folk Pharmacopoeia in London. Journal of Ethnopharmacology 120: 342-59.

Cocks ML, Bangay L, Shackleton CM, Wiersum KF (2008) 'Rich Man Poor Man' Inter-Household And Community Factors Influencing The Use Of Wild Plant Resources Amongst Rural Households In South Africa. International Journal of Sustainable Development 15: 1-13.

Cooper H (2009) Research sysnthesis and meta-analysis: a step-by-step approach. 4. ed. SAGE, California.

Douwes E, Crouch NR, Edwards TJ, Mulholland DA (2008) Regression analyses of southern African ethnomedicinal plants: informing the targeted selection of bioprospecting and pharmacological screening subjects. Journal of Ethnopharmacology 119(3): 356-64.

Fisher M (1999) Household Welfare and Forest Dependence in Southern Malawi. Environment and Development Economics 9: 135-154.

Gaston KJ, Blackburn TM (2000) Pattern and Process in Macroecology. Blackwell Science, London.

Gavin M, Anderson G (2007) Socioeconomic Predictors of Forest Use Values in the Peruvian Amazon: A Potential Tool for Biodiversity Conservation. Ecological Economics 60: 752-762.

Glass G (1976) Primary, Secondary, and Meta-Analysis of Research. Educational Researcher 5: 3-8.

Hernández T, Canales M, Caballero J, Durán A, Lira R (2005) Análisis cuantitativo del conocimiento tradicional sobre plantas utilizadas para el tratamiento de enfermedades gastrointestinales en Zapotitlán de las Salinas, Puebla, México. Interciencia 30(9): 529-535.

Isaac NJ, Mallet J, Mace GM (2004) Taxonomic Inflation: It's Influence on Macroecology and Conservation. Trends in Ecology \& Evolution 19: 464-9.

Jennings S, Blanchard JL (2004) Fish Abundance with No Fishing: Predictions Based On Macroecological Theory. Journal of Animal Ecology 73: $632-642$.

Kapur SK, Shahi AK, Sarin YK, Moerman DE (1992) The medicinal flora of MajouriKirchi forests (Jammu and Kashmir State), India. Journal of Ethnopharmacology 36(1): 87-90.

Kelt DA., Van Vuren DH (2001) The Ecology and Macroecology of Mammalian Home Range Area. The American Naturalist 157: 637-645.

Leonti MAL, Ramirez F, Ticher O, Heinrich M (2003) Medicinal flora of the Popoluca, México: a botanical systematical perspective. Economic Botany 57(2): 218-230. 
Lucena RF, Araújo EL, Albuquerque UP (2007) Does The Local Availability Of Woody Caatinga Plants (Northeastern Brazil) Explain Their Use Value? Economic Botany 61: 347-361.

Medeiros PM, Soldati GT, Alencar NL, Vandebroek I, Pieroni A, Hanazaki N, Albuquerque UP (2012) The Use of Medicinal Plants by Migrant People: Adaptation, Maintenance, and Replacement. Evidence-Based Complementary and Alternative Medicine 2012: 1-12.

Moerman DE (1979) Symbols and selectivity: a statistical analysis of native American medical ethnobotany. Journal of Ethnopharmacology 1: 111-119.

Moerman DE (1989) Poisoned Apples and Honeysuckles: The Medicinal Plants of Native America. Medical Anthropology Quarterly 3(1): 52-61.

Moerman DE (1991) The medicinal flora of native North America: an analysis. Journal of Ethnopharmacology 31: 1-42.

Moerman DE (1996) An analysis of the food plants and drug plants of native North America. Journal of Ethnopharmacology 52(1): 1-22.

Moerman DE, Pemberton RW, Kiefer D (1999) A comparative analysis of five medicinal floras. Journal of Ethnobiology 19(1): 49-67.

Molares S, Ladio A (2009) Ethnobotanical review of the Mapuche medicinal flora: use patterns on a regional scale. Journal of Ethnopharmacology 122: 251-260.

Monteiro JM, Albuquerque UP, Lins-Neto EMF, Araújo EL, Amorim EL (2006) Use Patterns and Knowledge Of Medicinal Species Among Two Rural Communities In Brazil's Semi-Arid Northeastern Region. Journal of Ethnopharmacology 105: 173-86.

Monteiro JM, Araújo EL, Amorim EL, Albuquerque UP (2010) Local Markets and Medicinal Plant Commerce: A Review with Emphasis on Brazil. Economic Botany 64: 352-366.

Phillips O, Gentry AH (1993) The Useful Plants of Tambopata, Peru: I. Statistical Hypotheses Tests with a New Quantitative Technique. Economic Botany 47:1532.

Pieroni A, Gray C (2008) Herbal and Food Folk Medicines of the Russlanddeutschen Living in Künzelsau/Taläcker, South-Western Germany. Phytotherapy Research 22: 889-901.

Rangel TF, Diniz-Filho JA (2006) Towards An Integrated Computational Tool for Spatial Analysis in Macroecology and Biogeography. Global Ecology and Biogeography 15: 321-327.

Saslis-Lagoudakis CH, Williamson EM, Savolainen V, Hawkins JA (2011) Crosscultural comparison of three medicinal floras and implications for bioprospecting strategies. Journal of Ethnopharmacology 135(2): 476-87.

Smith FA, Lyons SK, Morgan Ernest S, Brown JH (2008) Macroecology: More than the Division of Food and Space among Species on Continents. Progress in Physical Geography 32: 115-138.

Soldati GT, Albuquertque UP (2012) A New Application for the Optimal Foraging Theory: The Extraction of Medicinal Plants. Evidence-Based Complementary and Alternative Medicine 2012: 364564.

Taylor CM, Gotelli NJ (1994) The Macroecology of Cyprinella: Correlates of Phylogeny, Body Size, and Geografical Range. The American Naturalist 144: 549-569.

Teklehaymanot T, Giday M, Medhin G, Mekonnen Y (2007) Knowledge and Use of Medicinal Plants by People around Debre Libanos Monastery in Ethiopia. Journal of Ethnopharmacology 111: 271-283. 
Albuquerque and Medeiros 2012. Systematic Reviews and Meta-Analysis Applied to Ethnobiological Research. Ethnobio Conserv 1:6

Vaughn CC, Taylor CM (2000) Macroecology of a Host-Parasite Relationship. Ecography 23: 11-20.

Volpato G, Godínez D, Beyra A, Barreto A (2009) Uses of Medicinal Plants by Haitian Immigrants and Their Descendants in the Province of Camagüey, Cuba. Journal of Ethnobiology and Ethnomedicine 5: 16. 